\title{
Two-port method for laparoscopically assisted vaginal hysterectomy: approach and outcomes
}

\author{
Jong Woon Bae • Un Suk Jung • Joong Sub Choi • \\ Jung Hun Lee $\cdot$ Chang Eop Son • Seung Wook Jeon • \\ Jin Hwa Hong
}

Received: 23 April 2010 / Accepted: 6 July 2010 /Published online: 28 July 2010

(C) Springer-Verlag 2010

\begin{abstract}
The aim of our study was to assess the feasibility and efficacy of laparoscopically assisted vaginal hysterectomy (LAVH) with the two-port method. One hundred seventy-six women with uterine diseases underwent LAVH using the two-port method. We reviewed the medical records of the patients' age, parity, body mass index, history of previous abdominal surgery, operative indications, histopathological diagnosis, operating time, weight of the removed uterus, change in the hemoglobin levels, hospital stay, and occurrence of any complications. The median age of the patients was 46 years (range, 3360 years), the median parity was 2 (range, $0-5$ ), and the median body mass index was $23.4 \mathrm{~kg} / \mathrm{m}^{2}$ (range, 17.6$29.6 \mathrm{~kg} / \mathrm{m}^{2}$ ). Forty-two patients $(23.9 \%)$ had previous abdominal operative history. The most common operative indication was menorrhagia, and the most common histopathological diagnosis was leiomyoma. The median operating time was $58 \mathrm{~min}$ (range, 30-150 $\mathrm{min}$ ), and the median
\end{abstract}

Jong Woon Bae and Un Suk Jung contributed equally to this work.

Electronic supplementary material The online version of this article (doi:10.1007/s10397-010-0611-2) contains supplementary material, which is available to authorized users.

\section{U. S. Jung}

Department of Obstetrics and Gynecology, Konyang University Hospital, Konyang University College of Medicine,

Daejeon, Republic of Korea

J. W. Bae $\cdot$ J. S. Choi $(\bowtie) \cdot$ J. H. Lee $\cdot$ C. E. Son $\cdot$ S. W. Jeon $•$

J. H. Hong

Division of Gynecologic Oncology and Gynecologic Minimally

Invasive Surgery, Department of Obstetrics and Gynecology,

Kangbuk Samsung Hospital,

Sungkyunkwan University School of Medicine,

108, Pyung-dong, Jongno-gu,

Seoul 110-746, Republic of Korea

e-mail: yjjy.choi@samsung.com weight of the removed uterus was $230 \mathrm{~g}$ (range, 60-660 g). The median change in the hemoglobin level was $1.7 \mathrm{~g} / \mathrm{dL}$ (range, $0.1-3.8 \mathrm{~g} / \mathrm{dL}$ ). The median hospital stay was 3 days (range, 2-7 days). An ileus occurred postoperatively in one patient, which was managed conservatively. No additional port was required in any of the cases. No operation was converted to an abdominal hysterectomy. LAVH using the two-port technique with the aid of a 5-mm telescope and an endoscopic stapler is both feasible and efficient.

Keywords Hysterectomy · Laparoscopy · Surgical stapler . Port

\section{Background}

Laparoscopically assisted vaginal hysterectomy (LAVH) is one of the most frequently performed gynecologic operations, and numerous authors have demonstrated the safety and feasibility of LAVH [1]. Researchers have performed LAVH on variously sized uteri with broad indications and have successfully introduced methods that reduce morbidity [2-4]. The three- or four-port method with various portplacement systems is used in most laparoscopic hysterectomies. The aim of our study was to evaluate the feasibility and efficacy of LAVH with the two-port method using a 5 -mm telescope and endoscopic staplers.

\section{Materials and methods}

Eight hundred seventy-nine women with various uterine diseases underwent LAVH at Kangbuk Samsung Hospital from December 2005 to June 2009. Among those, 176 women $(19.2 \%)$ underwent LAVH utilizing the two-port 
method. For the rest, including 18 single-port method, either the three-port method or the four-port method was used [2]. All patients underwent preoperative assessments that included a detailed medical history, pelvic examination, pelvic ultrasonogram, and Pap smear. When indicated, a colposcopically directed cervical biopsy, conization of the uterine cervix, or endometrial biopsy was performed preoperatively. Information such as age, parity, body mass index, the number of previous abdominal surgery, operative indications, histopathological results, weight of the extracted uterus, operating time, hemoglobin level, and operative complications were collected by investigating surgical and anesthetic records. Operating time was defined as the time from the first umbilical incision to the skin closure. Informed consents were obtained in all the cases.

Patients routinely underwent general anesthesia with endotracheal intubation followed by the placement of a uterine manipulator in a dorsal lithotomy position. Cefazedone sodium $(1 \mathrm{~g})$ was injected intravenously $30 \mathrm{~min}$ before the induction of anesthesia. After lifting the anterior abdominal wall, a 5-mm port was directly inserted at the infraumbilicus with a vertical skin incision. Carbon dioxide was insufflated through the port sleeve to create a pneumoperitoneum, and the intra-abdominal pressure was maintained at $15 \mathrm{mmHg}$. The intra-abdominal cavity was inspected with a 5-mm telescope. Transillumination was used to locate the superior and inferior epigastric vessels, and direct visualization was used to insert a secondary ancillary 5-mm port into the left upper quadrant. The 5-mm infraumbilical port was replaced with a $12-\mathrm{mm}$ port (Fig. 1). If adhesiolysis was necessary, bipolar grasping forceps and endoscissors were inserted sequentially into the left upper quadrant port site. The 5-mm telescope was shifted to the left upper quadrant 5 -mm port, and an endoscopic stapler (Endoscopic Linear Cutter ${ }^{\circledR}$, Ethicon Endo-surgery, Cincinnati, OH, USA) was inserted into the umbilical 12-mm port. An assistant moved the uterus using the uterine manipulator on tension to one side. At the same time, the ovarian ligament, the salpinx, and the round ligament were simultaneously transected by the endoscopic stapler. This procedure was repeated on the contralateral side. A bladder flap was created by dissecting the broad ligament in front of the uterine artery with the endoscissors. If necessary, the ovary was removed by simultaneously transecting the infundibulopelvic ligament and the round ligament with the endoscopic stapler. When the laparoscopic step was completed, the carbon dioxide gas was removed, and vaginal portion of the procedure was performed in the usual fashion. The vaginal vault was sutured after insertion of a Foley catheter. Once again, the abdomen was insufflated, a survey was performed to ensure hemostasis, and we have confirmed any possible ureteric injuries in all operations by observing and identifying the

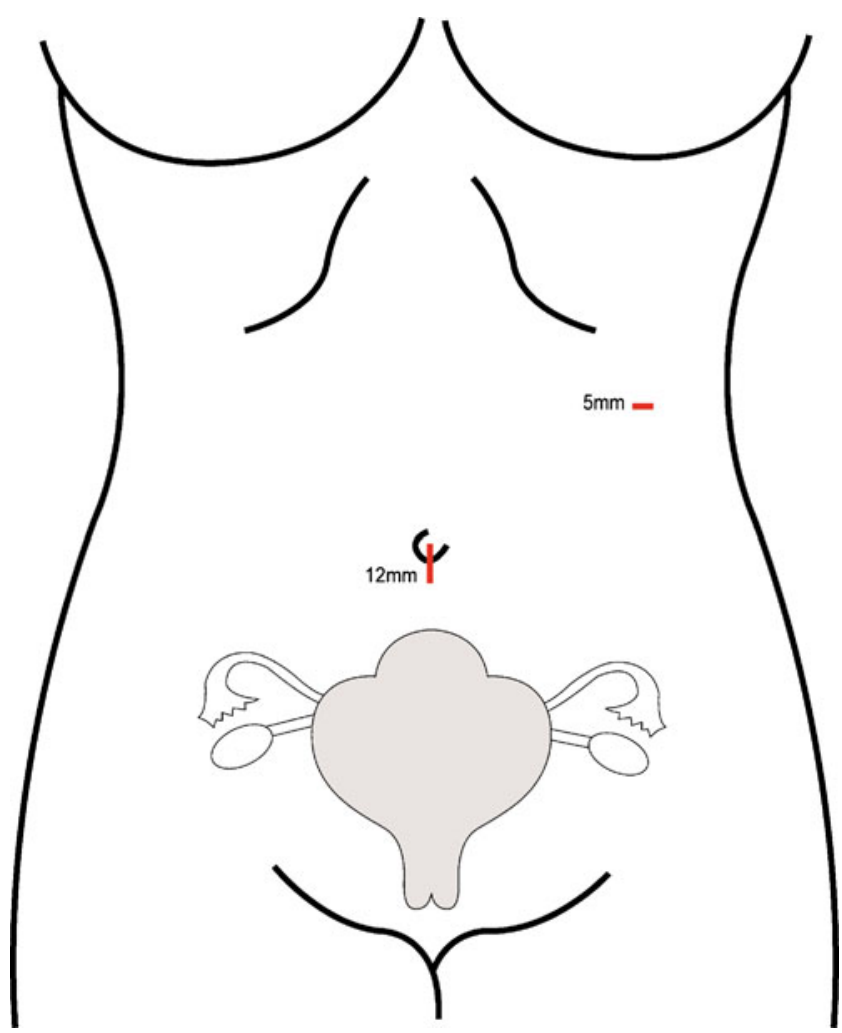

Fig. 1 Port-placement system for LAVH with the two-port method. The 5-mm telescope was located on the left upper quadrant 5-mm port site and an endoscopic stapler in the umbilical $12-\mathrm{mm}$ port site

peristalsis, the absence of dilation of the both ureters after surgery, and by tracing its direction to the bladder (Fig. 2). A drainage tube was inserted into the left upper quadrant through the 5-mm port in some patients when persistent oozing was present or adhesiolysis had been performed.

The SAS program (version 9.1; SAS Institute Inc., Cary, $\mathrm{NC}$, USA) was used for all statistical analyses.

\section{Findings}

During the study period, 176 women underwent LAVH with the two-port method. Table 1 presents the demographic and operative characteristics of the patients. Forty-two women (23.9\%) had previous abdominal operative history, most commonly cesarean section (25 out of $176,14.2 \%$ ). The most common surgical indication was menorrhagia (102 out of 176, 58.0\%), and the most frequent histopathological diagnosis was leiomyoma (118 out of $176,67.0 \%$ ). The median weight of the resected uterus was $230 \mathrm{~g}$ (range, $60-660 \mathrm{~g}$ ). The median operating time was $58 \mathrm{~min}$ (range, $30-150 \mathrm{~min}$ ). The median change in the hemoglobin level from before surgery to postoperative day 1 was $1.7 \mathrm{~g} / \mathrm{dL}$ (range, $0.1-3.8 \mathrm{~g} / \mathrm{dL}$ ). The median hospital stay was 3 days (range, 2-7 days). None of the cases required an additional 
Fig. 2 Sequential images of LAVH with the two-port method. a Laparoscopic view of uterus with multiple myomas. b Transection of the left ovarian ligament, salpinx, and round ligament with an endoscopic stapler through the umbilical 12-mm port site. c Transection of the right ovarian ligament, salpinx, and round ligament using the same method. d Immediate postoperative view

Table 1 Patients' characteristics and operative outcome for the two-port method
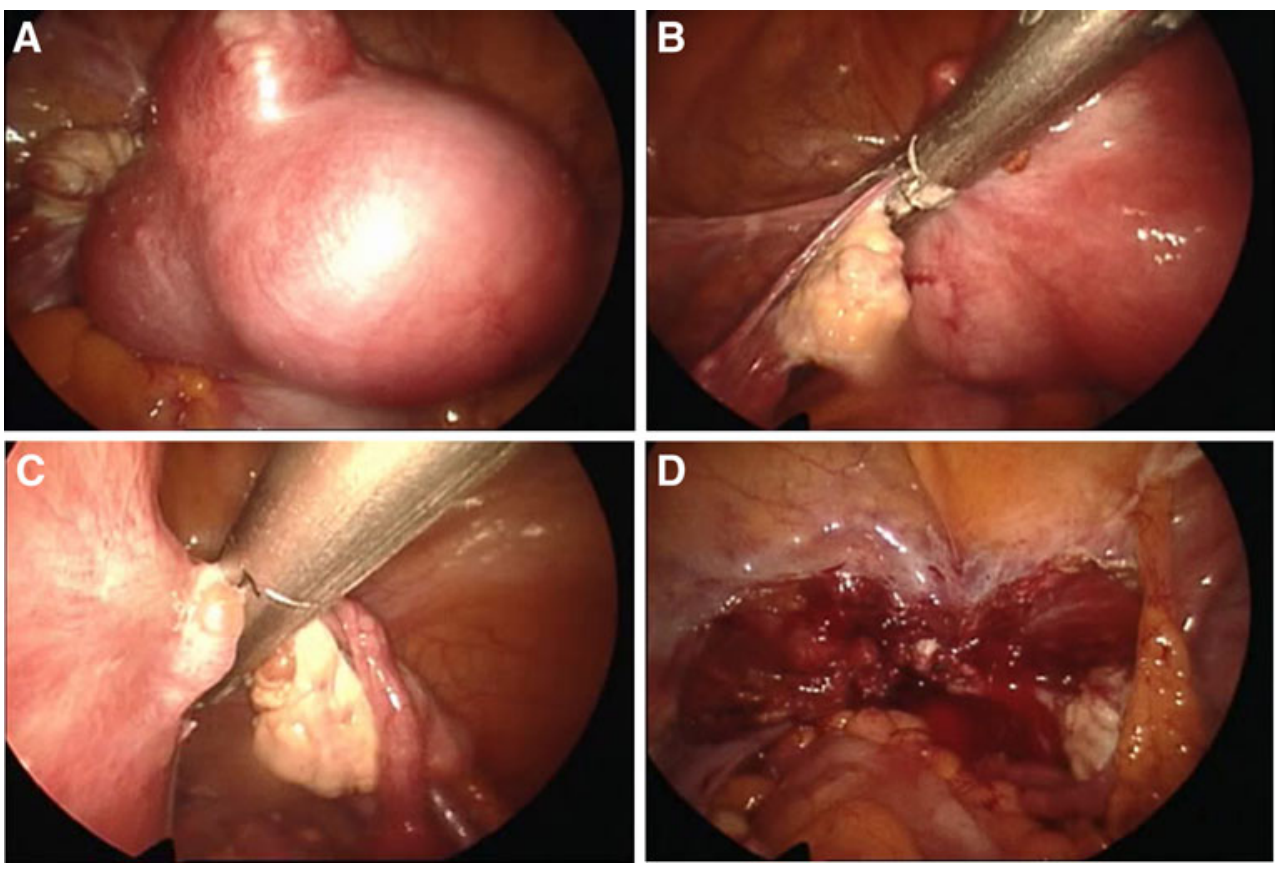

Characteristics

Age (years)

Parity

Body mass index $\left(\mathrm{kg} / \mathrm{m}^{2}\right)$

Operating time (min)

Uterine weight of removed specimen $(\mathrm{g})$

Hospital stay (day)

Estimated blood loss (mL)

Hemoglobin change $(\mathrm{g} / \mathrm{dL})$

Complications $(\%)$

Conversion to laparotomy (\%)

Indications for LAVH

Menorrhagia

Lower abdominal pain

Carcinoma in situ of the uterine cervix

Dysmenorrhea

Microinvasive SCC of the uterine cervix

Previous abdominal surgery

Cesarean section

Appendectomy

Adnexectomy

Myomectomy

Histopathological diagnosis

Leiomyoma

Adenomyosis

Carcinoma in situ of the uterine cervix

Microinvasive SCC of the uterine cervix
Median (range), number (\%)

$46(33-60)$

$2(0-5)$

$23.4(17.6-29.6)$

$58(30-150)$

$230(60-660)$

$3(2-7)$

$200(45-800)$

$1.7(0.1-3.8)$

$1(0.006)$

0 (0)

Number of subjects $(n=176 ; \%)$ $102(58.0)$

$41(23.3)$

$17(9.7)$

$14(8.0)$

$2(1.1)$

Number of subjects $(n=42 ; \%)$

25 (14.2)

$7(4.0)$

$6(3.4)$

$4(2.3)$

Number of subjects $(n=176 ; \%)$

$118(67.0)$

39 (23.3)

$17(9.7)$

$2(1.1)$ 
port placement. There was no conversion to laparotomy in any cases. Eleven patients $(6.3 \%)$ with anemia caused by menorrhagia received transfusion before or during the operation. No other intraoperative complications were noted. One case was complicated with an ileus postoperatively, but it was resolved with conservative treatment. All patients visited at 7 days, 2 months, and 12 months after two-port LAVH. There were no surgery-related complications.

\section{Discussion}

Since LAVH was first introduced in 1989 by Reich et al., various forms of laparoscopic hysterectomy such as laparoscopic supracervical hysterectomy or classic intrafascial supracervical hysterectomy, LAVH, and total laparoscopic hysterectomy have been developed and modified [5-9]. LAVH has remained the widely performed method and the frequent type of laparoscopic hysterectomy.

Laparoscopic hysterectomy has earlier recovery, less postoperative pain, and cosmetic advantage when compared to conventional abdominal hysterectomy [10]. The number and size of ports used during laparoscopic surgery have been reported to be correlated with pain and analgesic use postoperatively [11-13]. Moreover, multiple skin incisions can lessen the patient's satisfaction postoperatively.

A study of two-port and four-port laparoscopic cholecystectomy showed higher patient satisfaction scores on the scar in two-port than four-port group [14], and Al-Azawi et al. have demonstrated increased pain with increasing numbers of ports, especially more than four [15].

One of the unique techniques we used in this study is placement of the ports at the umbilicus and left upper quadrant. The vesicouterine peritoneum was easily accessed through the left upper quadrant port and, subsequently, the umbilical port. Instrument handling was convenient, and visibility was equally adequate using both the umbilical and left upper quadrant port sites. In a comparable study using two ports, a 2-mm minilaparoscope is fixed in the right lower quadrant, and the use of a laparoscopic instrument was possible only through the umbilical port [16]. Therefore, dissecting the vesicouterine peritoneum is not possible using this laparoscopic approach; thus, visualization and identification of the peritoneum are instead performed using a light-endorsed transvaginal section in the vaginal phase. Also, there has been a study on two-port LAVH using supraumbilical multichannel port and an ancillary port, but this method needed a $15-\mathrm{mm}$ incision in the supraumbilical area for insertion of multichannel port. On the other hand, we used one $12-\mathrm{mm}$ trocar and one 5-mm trocar [5].

Port insertion in the LUQ can decrease the risk of ilioinguinal or iliohypogastric nerve injury and nerve entrapment syndrome [2]. Therefore, this two-port method seems to offer cosmetic satisfaction to the patients, less pain, fast recovery, and less port-associated complications. We used the endoscopic stapler device for dissecting and hemostasis in this study. It is widely used for these purposes, and its safety and utility have already been demonstrated in laparoscopic hysterectomy $[17,18]$.

However, if necessary, additional placement of ports should be performed to complete the procedure: severe adhesions, adnexal pathology, and large fibroids. Future areas of interest should include a direct comparison between LAVH using two-port method and conventional three- or four-port method.

LAVH using two ports, including a 5-mm telescope, was performed successfully for various benign uterine diseases in adequate operation times, without serious complications and increased surgical morbidity. LAVH with the two-port method is feasible and efficient with proper port placement, available laparoscopic instruments, and a suitable patient selection. But this is a retrospective study, so a randomized or comparative study will be required to determine the difference of pain and recovery between conventional and two-port LAVH.

Conflicts of interest The authors report no conflicts of interest. The authors alone are responsible for the content and writing of the paper.

\section{References}

1. Shen CC, Wu MP, Lu CH, Huang EY, Chang HW, Huang FJ, Hsu TY, Chang SY (2003) Short- and long-term clinical results of laparoscopic-assisted vaginal hysterectomy and total abdominal hysterectomy. J Am Assoc Gynecol Laparosc 10:49-54

2. Choi JS, Kyung YS, Kim KH, Lee KW, Han JS (2006) The fourtrocar method for performing laparoscopically-assisted vaginal hysterectomy on large uteri. J Minim Invasive Gynecol 13:276-280

3. Ferrari MM, Berlanda N, Mezzopane R, Ragusa G, Cavallo M, Pardi G (2000) Identifying the indications for laparoscopically assisted vaginal hysterectomy: a prospective, randomised comparison with abdominal hysterectomy in patients with symptomatic uterine fibroids. BJOG 107:620-625

4. Darai E, Soriano D, Kimata P, Laplace C, Lecuru F (2001) Vaginal hysterectomy for enlarged uteri, with or without laparoscopic assistance: randomized study. Obstet Gynecol 97:712-716

5. Yi SW, Park HM, Lee SS, Park SM, Lee HM, Sohn WS (2009) Two-port total laparoscopic hysterectomy with a multichannel port. J Laparoendosc Adv Surg Tech A 19:223-228

6. Reich H, DeCaprio J, McGlynn F (1989) Laparoscopy hysterectomy. J Gynecol Surg 5:213

7. Reich H, McGlynn F, Sekel L (1993) Total laparoscopic hysterectomy. Gynecol Endosc 2:59-63

8. Jenkins TR (2004) Laparoscopic supracervical hysterectomy. Am J Obstet Gynecol 191:1875-1884

9. Johnson N, Barlow D, Lethaby A, Tavender E, Curr E, Garry R (2006) Surgical approach to hysterectomy for benign gynaecological disease. Cochrane Database Syst Rev (2):CD003677

10. Nieboer TE, Johnson N, Lethaby A, Tavender E, Curr E, Garry R, van Voorst S, Mol BWJ, Kluivers KB (2009) Surgical approach to 
hysterectomy for benign gynaecological disease. Cochrane Database Syst Rev (3):CD003677. doi:10.1002/14651858.CD003677.pub4

11. Gagner M, Garcia-Ruiz A (1998) Technical aspects of minimally invasive abdominal surgery performed with needlescopic instruments. Surg Laparosc Endosc 8:171-179

12. Bisgaard T, Klarskov B, Trap R, Kehlet H, Rosenberg J (2000) Pain after microlaparoscopic cholecystectomy. A randomized double-blind controlled study. Surg Endosc 14:340-344

13. Leggett PL, Churchman-Winn R, Miller G (2000) Minimizing ports to improve laparoscopic cholecystectomy. Surg Endosc 14:32-36

14. Poon CM, Chan KW, Lee DW, Chan KC, Ko CW, Cheung HY, Lee KW (2003) Two-port versus four-port laparoscopic cholecystectomy. Surg Endosc 17:1624-1627
15. Al-Azawi D, Houssein N, Rayis AB, McMahon D, Hehir DJ (2007) Three-port versus four-port laparoscopic cholecystectomy in acute and chronic cholecystitis. BMC Surg 7:8

16. Tsai EM, Chen HS, Long CY, Yang CH, Hsu SC, Wu CH, Lee JN (2003) Laparoscopically assisted vaginal hysterectomy versus total abdominal hysterectomy: a study of 100 cases on lightendorsed transvaginal section. Gynecol Obstet Investig 55:105109

17. Lee CL, Soong YK (1993) Laparoscopic hysterectomy with the Endo GIA 30 stapler. J Reprod Med 38:582-586

18. McMaster-Fay R (2004) Endoscopic stapling of large uterine vessels at laparoscopic hysterectomy for uterine fibroid masses of 500 g or more: a pilot study. Gynecol Surg 1:195-197. doi:10. 1007/s10397-004-0046-8 